\title{
The Sexual Differentiation of the Human Brain: Role of Sex Hormones Versus Sex Chromosomes
}

\author{
Julie Bakker
}

\section{Contents}

1 Introduction

1.1 Sex Determination and Sexual Differentiation

1.2 Sexual Differentiation of the Brain: Animal Studies

1.3 Sexual Differentiation of the Human Brain

1.4 Indirect Measures of Prenatal Hormone Levels

1.5 Postmortem Studies

1.6 Clinical Studies

1.7 The Sexual Differentiation of the Human Brain: Neuroimaging Studies in CAIS

2 Concluding Remarks

References

\begin{abstract}
Men and women differ, not only in their anatomy but also in their behavior. Research using animal models has convincingly shown that sex differences in the brain and behavior are induced by sex hormones during a specific, hormone-sensitive period during early development. Thus, male-typical psychosexual characteristics seem to develop under the influence of testosterone, mostly acting during early development. By contrast, female-typical psychosexual characteristics may actually be organized under the influence of estradiol during a specific prepubertal period. The sexual differentiation of the human brain also seems to proceed predominantly under the influence of sex hormones. Recent studies using magnetic resonance imaging have shown that several sexually differentiated aspects of brain structure and function are female-typical in women with complete androgen insensitivity syndrome (CAIS), who have a 46 XY karyotype but a female phenotype due to complete androgen resistance, suggesting that these sex differences most likely reflect androgen action, although feminizing effects of estrogens or female-typical socialization cannot be ruled out. By contrast, some male-typical neural characteristics were also observed in women with CAIS suggesting direct effects of sex chromosome genes in the sexual differentiation of the human brain.
\end{abstract}

\footnotetext{
J. Bakker (凶)

Laboratory of Neuroendocrinology, GIGA Neurosciences, Liège University, Liège, Belgium e-mail: jbakker@uliege.be
} 
In conclusion, the sexual differentiation of the human brain is most likely a multifactorial process including both sex hormone and sex chromosome effects, acting in parallel or in combination.

Keywords Androgens · Brain function · Brain structure $\cdot$ Complete androgen insensitivity syndrome $\cdot$ Estrogens $\cdot$ Magnetic resonance imaging $\cdot$ Sex differences · Sexual development

\section{Introduction}

Although men and women might be more similar than different, notable sex differences exist in cognitive abilities (Maccoby and Jacklin 1974), brain morphology (Cosgrove et al. 2007), emotion processing (Schirmer et al. 2004), and vulnerability to psychiatric disorders (Bao and Swaab 2011). The origin of these sex differences in the brain and behavior remains the subject of heated debate. In particular, whether sex differences observed in adulthood result from specific biological processes occurring during early development ("nature") or from the (social) environment ("nurture") has been contested. There is increasing evidence, however, that the organization of the brain is affected by circulating sex hormones and the expression of specific genes during early development and thus that sex differences in brain structure and organization are already present as early as birth. The biological bases of sex differences in brain and behavior are becoming better known, but many questions remain about how sex hormones induce such different patterns of neural and behavioral differentiation in men and women. This chapter will provide a short overview of our current knowledge of how the sexual differentiation of the human brain proceeds under the influence of organizing actions of sex hormones. For obvious ethical reasons, many of our ideas about the sexual differentiation of the human brain are derived from (clinical) research on patients with disorders of sex development (DSD).

\subsection{Sex Determination and Sexual Differentiation}

In mammals, including humans, the developing organism has the potential to become either male or female. The first step in the process of sex determination is the establishment of the genetic sex at conception. Each cell nucleus contains a species-specific number of paired autosomes and two sex chromosomes. Humans have 22 pairs of autosomes and one pair of sex chromosomes (the $\mathrm{X}$ and $\mathrm{Y}$ ). Autosomes are numbered roughly in relation to their sizes, i.e., chromosome 1 has approximately 2,800 genes, whereas chromosome 22 has approximately 750 genes. The sex chromosomes will determine the sex of the fetus: females have two $\mathrm{X}$ chromosomes, whereas males have one $\mathrm{X}$ and $\mathrm{Y}$ chromosome. The latter contains 
the Sry gene, which will induce the formation of testes from the undifferentiated gonads in males (Koopman et al. 1990). The Leydig cells in the testes will produce testosterone which will promote the development of the Wolffian ducts into the internal male genital structures such as the epididymis, the vas deferens, and the seminal vesicles, whereas anti-Müllerian hormone secreted by the Sertoli cells in the testes causes regression of the female-typical Müllerian ducts. The penis and scrotum develop under the influence of dihydrotestosterone which is formed from testosterone by the enzyme, $5 \alpha$-reductase. In typical female differentiation, i.e., in the absence of the Y chromosome and consequently the Sry gene, the undifferentiated gonads will develop into ovaries. The Müllerian ducts develop without any apparent hormonal input into the uterus, fallopian tubes, and the distal portion of the vagina, whereas the Wolffian ducts regress and disappear in the absence of androgenic stimulation.

\subsection{Sexual Differentiation of the Brain: Animal Studies}

Animal studies have convincingly shown that the sexual differentiation of the brain generally follows the same pattern as that of the genitals, i.e., exposure to testosterone induces male-typical psychosexual and neural characteristics, whereas in the absence of testosterone, female-typical psychosexual and neural characteristics develop, i.e., by default. This is mainly based on studies in rodents in which the testes were removed directly after birth or conversely, when testosterone was administered to newborn females. It was found that neonatally castrated male rats showed very few male-typical sexual behaviors even following administration of testosterone in adulthood (Grady et al. 1965), whereas testosterone-treated females showed increased levels of male-typical sexual behaviors, such as mounting behavior (reviewed in Baum 1979). In addition, when treated with "femaletypical" sex hormones, i.e., estradiol and progesterone, neonatally castrated male rats showed female-typical sexual behaviors, like the expression of the typical female rodent mating posture, lordosis (Feder and Whalen 1964). This led to the conclusion that the female-typical differentiation of the brain proceeds in the absence of any hormonal secretion, i.e., by default. This was further supported by the finding that the ovaries are functionally quiescent during early development: no significant amounts of estradiol could be detected before postnatal day 7 (Lamprecht et al. 1976), whereas the testes start to produce testosterone about 1 week before birth in rodents. However, more recent studies have shown that estradiol may be required for the development of the female brain. Female aromatase knockout (ArKO) mice which carry a targeted mutation in the aromatase gene and as a result cannot synthesize estrogens from androgens, show reduced levels of female sexual behavior in adulthood, even following ovariectomy and subsequent treatment with estradiol and progesterone (Bakker et al. 2002). Interestingly, administration of estradiol over a specific prepubertal period (postnatal days P15-P25) almost completely restored female sexual behavior in 
female ArKO mice (Brock et al. 2011). This result clearly challenges the classical theory of a default organization of the female brain. It also challenges the idea that sex differences are established before or directly after birth and that sex hormones beyond the perinatal period only have so-called "activational" effects on the brain. Hence, it might be well possible that the brain remains plastic and sensitive to any organizational actions of sex hormones for a much longer period as initially thought.

Although very little doubt remains on the pivotal role of gonadal hormones in establishing sex differences in the brain and behavior, some evidence has been emerging that genes on the sex chromosomes might also contribute to the sexual differentiation of the brain (Arnold et al. 2004). By using a core-cross transgenic mouse model in which the Sry gene was deleted from the Y chromosome and inserted into an autosome to create $\mathrm{XX}$ and $\mathrm{XY}$ male and female phenotypes, it was possible to distinguish between the contribution of gonadal hormones and sex chromosome genes to the development of sex differences in the brain and behavior. It was shown, for instance, that the male-typical profile of vasopressin innervation of the lateral septum depends on the presence of a Y chromosome (de Vries et al. 2002). $\mathrm{XY}$ males and XY female mice (i.e., females with a deletion of the Sry gene) were more masculine than $\mathrm{XX}$ mice in the density of vasopressin-immunoreactive fibers in the lateral septum. Based on these findings, it has been proposed that the mechanism of sexual differentiation is multifactorial and includes both sex hormone and sex chromosome effects, acting in parallel or in combination (Arnold 2017).

\subsection{Sexual Differentiation of the Human Brain}

An important question raised by animal studies is that if sex hormones play such a pivotal role in masculinizing or feminizing the brains of nonhuman species, do they have similar actions in our own species? In other words, do men and women behave differently because men have been exposed to higher concentrations of testosterone during development or conversely, women to higher levels of estrogens? In humans the sexual differentiation of brain is thought to occur between 8 and 24 weeks of gestation when testosterone levels are higher in male than female fetuses (Reyes et al. 1974; Nagamani et al. 1979). Furthermore, the first months after birth are also marked by a testosterone surge in boys, peaking at around 3 months after birth, and increased estradiol levels in girls, which decrease more gradually during the second year of life (Winter et al. 1976; Kuiri-Hänninen et al. 2014). This period is often referred to as "mini-puberty" (Kuiri-Hänninen et al. 2014), is most likely caused by an increased gonadotropin secretion since there is no longer any negative feedback by estrogens after birth, and might be an additional critical period for organizational actions of sex hormones on the brain and behavior. 


\subsection{Indirect Measures of Prenatal Hormone Levels}

For obvious ethical reasons, indirect markers of prenatal hormone levels have been used to study potential organizational effects of sex hormones in the human brain. The 2D:4D ratio, i.e., the relative length of the second to the fourth digit, which is larger in women than men (Hönekopp and Watson 2010), is the most extensively used marker (Morris et al. 2004), because it is so easy to obtain, a simple photocopy of the hand suffices. However, its validity as an indicator of prenatal androgen exposure has been criticized (Berenbaum et al. 2009; van Hemmen et al. 2017a). Firstly, two independent studies (Lutchmaya et al. 2004; Ventura et al. 2013) have actually attempted to measure fetal androgen levels through amniocentesis and to correlate them with digit ratios, but their results were inconclusive. Secondly, the results obtained in women with complete androgen insensitivity syndrome (CAIS) strongly suggest that other non-androgenic factors are also involved (van Hemmen et al. 2017a). Otoacoustic emissions (OAE) are sounds produced by the cochlea, which can be measured in the inner ear canal (Kemp 1978, 2008; Davis 1983), and are another marker used for assessing prenatal hormone exposure retrospectively. Spontaneous OAEs are more frequent and stronger in women than in men. Likewise, OAEs evoked by click stimuli have larger amplitudes in women than in men (McFadden and Pasanen 1998; Shinur and Hampson 2011). These two measures have in particularly been used to assess whether sexual orientation might reflect changes in prenatal androgen exposure (for comprehensive review, see Breedlove 2017). It was found, however, that homosexual men showed very similar 2D:4D ratios and OAEs as heterosexual men. By contrast, lesbian women showed "masculinized" 2D:4D ratios and OAEs suggesting that they might have been exposed to increased levels of androgens during early development. Although these markers might be useful to determine early androgen exposure, they have many limitations since they can only be used retrospectively and might also be affected by circulating hormone levels in adulthood. This has particularly been suggested for OAEs (Shinur and Hampson 2011).

\subsection{Postmortem Studies}

Postmortem analyses of the brain have been an important method to determine whether sex differences in human behavior, but also differences related to sexual orientation and gender identity, could be explained by structural differences in the brain. Many of these studies have been inspired by observations made in animal studies. For instance, the discovery of a sexually dimorphic nucleus (SDN) in the rat preoptic area led to a close examination of the human preoptic area where a similar sexually dimorphic nucleus was observed (SDN or interstitial nucleus of the anterior hypothalamus (INAH-1 and 2)) which is larger in men than in women. However, no variations in the size of this nucleus have been observed in relation to sexual 
orientation (Swaab 2007). In addition, three independent groups have shown that a different nucleus in the anterior hypothalamus, INAH-3, is significantly larger in heterosexual men than in heterosexual women (Allen et al. 1989; Byne et al. 2001; Levay 1991), and in a highly publicized study (LeVay 1991), it was reported that the volume of INAH-3 was greater in heterosexual than in homosexual men, although this latter finding still awaits full replication (Byne et al. 2001). A rather unexpected finding (Swaab and Hofman 1990) was that the suprachiasmatic nucleus (SCN), the clock of the brain, was twice as large in homosexual men compared to heterosexual men, in particularly because no sex differences were observed. This finding suggests that homosexual men do not have a "female-typical" hypothalamus as has been proposed (Dörner 1988).

By contrast, female-typical volumes of the central nucleus of the bed nucleus of the stria terminalis (Zhou et al. 1995; Kruijver et al. 2000) and the INAH-3 (GarciaFalgueras and Swaab 2008) have been observed in male-to-female (MtF) transsexuals. Likewise, a female-typical expression of two neuropeptides important in regulating GnRH secretion, i.e., neurokinin B (Taziaux et al. 2012) and kisspeptin (Taziaux et al. 2016), has been found in the infundibular nucleus of the hypothalamus of MtF transsexuals. These results may suggest that transsexual people, which are now referred to as people diagnosed with gender dysphoria (defined as a strong incongruence between their gender assigned at birth and the gender that they identify with; DSM-5), have undergone an atypical sexual differentiation of the brain. However, some caution is warranted in interpreting the results because some of these effects might be due to adult hormone treatment (for instance, estrogen treatment in MtF transsexuals) or other not-yet-identified causes.

\subsection{Clinical Studies}

Perhaps more valuable insights into the mechanisms underlying the sexual differentiation of the human brain might be obtained by studying "disorders of sex development" also known as "disorders of sex differentiation" (DSD). The term DSD refers to congenital conditions in which the development of chromosomal, gonadal, or anatomical sex is atypical (as cited in Hughes et al. 2006). Although many DSDs are not well studied in this context because they are extremely rare, several DSDs provide a unique opportunity to assess the different players involved in sexual differentiation. Examples include, but are not limited to, congenital adrenal hyperplasia (CAH), sex chromosome aneuploidies, and complete androgen insensitivity syndrome (CAIS).

Congenital adrenal hyperplasia $(\mathrm{CAH})$ is the most common DSD $(1: 10,000)$ which is characterized in about $95 \%$ of the cases by a mutation in the gene encoding the enzyme 21-hydroxylase which is important for the conversion of progesterone to deoxycorticosterone. As a result, progesterone can only be converted to 17$\alpha$-hydroxyprogesterone (which in turn cannot be converted to 11-deoxycortisol). The lack of cortisol will lead to an increased release of adrenocorticotropic hormone 
(ACTH) by the anterior pituitary since cortisol normally has a negative feedback action on ACTH as well as on the secretion of its stimulator corticotropin-releasing hormone (CRH) from the paraventricular nucleus of the hypothalamus. This increased stimulation by ACTH induces overgrowth (hyperplasia) and hyperactivity of the steroid-producing cells of the adrenal cortex ultimately leading to an increased production of androgens during fetal life. At birth, 46, XX females often have ambiguous genitalia depending on the degree of exposure to androgens during fetal development. Starting early in childhood, girls with CAH also typically show masculinized patterns of sex-typed behavior such as toy and activity preferences, i.e., spending more time playing with boy's toys such as cars than girls' toys such as dolls, showing more rough and tumble play, and preferring boys over girls as playmates (Collaer and Hines 1995; Pasterski et al. 2005). In adulthood, CAH is often associated with polycystic ovarian syndrome (oligomenorrhea, polycystic ovaries, hirsutism) and increased incidence of bisexual orientation and gender dysphoria (Meyer-Bahlburg et al. 2008). In contrast, 46, XY boys with CAH do not show any clear symptoms other than those related to decreased cortisol production. These observations in girls/women with CAH suggest that prenatal androgens indeed might organize male-typical psychosexual and neurobehavioral characteristics.

Individuals with sex chromosome aneuploidies (SCAs) have an atypical number of sex chromosomes and often show deficits in certain cognitive domains (Printzlau et al. 2017), some of which showing sex differences in the general population. Therefore, SCAs have been suggested as a method to study possible effects of sex chromosome genes on the development of the brain. Klinefelter syndrome (KS; incidence, 1:500-1,000), characterized by two or more X chromosomes and a Y chromosome, thus male phenotype, and Turner syndrome (TS; incidence, 1:2,500), characterized by one $\mathrm{X}$ chromosome and a lack of (all or part) of the second $\mathrm{X}$ chromosome, thus female phenotype, have been mostly studied in this context. However most SCAs also result in atypical sex hormone levels, such as hypogonadism in men with $\mathrm{KS}$ prior to being supplemented with testosterone (Davis et al. 2015) and decreased estradiol production in women with TS due to premature ovarian failure (Modi et al. 2003). Consequently, it has been challenging to establish whether any findings obtained in these two SCAs represent direct genetic effects related to sex chromosome gene dosage, sex hormone effects, or both.

Androgen insensitivity syndrome (AIS) might be one of the most interesting DSDs to study the respective roles of sex hormones versus sex chromosome genes in the sexual differentiation of the human brain. AIS has an estimated incidence of 1:40,800 to 1:99,000 (Boehmer et al. 2001) and is characterized by a mild (MAIS), partial (PAIS), or complete (CAIS) defect in androgen action caused by mutation(s) in the Xchromosome-linked androgen receptor gene (Hughes et al. 2012), resulting in decreased or completely abolished AR function. The degree of androgen resistance determines the phenotypical presentation, ranging from a male phenotype with fertility problems in MAIS to mild or severe hypomasculinization and ambiguous genitalia in PAIS and a female phenotype in CAIS. In a fetus with CAIS, the gonads develop into testes under the influence of the SRY gene and start producing 
androgens and AMH. Due to the inability of androgens to activate the AR, the external genitalia develop in the female direction, whereas AMH causes regression of the Müllerian duct, resulting in a blind-ending vagina and absent uterus. CAIS is detected in infancy in case of an inguinal hernia or in adolescence in case of primary amenorrhea (Hughes et al. 2012). The assigned gender at birth and gender upbringing is typically female. With regard to secondary sex characteristics, pubic and axillary hair is either sparse or absent (Tadokoro-Cuccaro and Hughes 2014) since they depend on androgens. There is spontaneous breast development since testosterone is converted into estradiol by the enzyme aromatase, and CAIS might be more sensitive to estrogens (Zachmann et al. 1986). Because of an increased risk of gonadal tumor development in DSDs, including CAIS, the general medical advice is to surgically remove the gonads (Cools et al. 2006; Lee et al. 2016). Following gonadectomy, estrogen replacement therapy is initiated to induce puberty in case of prepubertal gonadectomy and to optimize bone health later on (Bertelloni et al. 2011). Studies on the psychosexual development of CAIS have generally shown an androphilic sexual orientation (i.e., sexual attraction to men), a female gender identity, and female-typical gender role behavior (Masica et al. 1971; Wisniewski et al. 2000; Hines et al. 2003) which is in line with a hypothesized role of androgens in the sexual differentiation of these psychosexual characteristics. Recent work (T'Sjoen et al. 2011; Brunner et al. 2016), however, showed that some individuals with CAIS reported other-than-female gender roles or neither-female-nor-male genders. In addition, not all CAIS reported an exclusively androphilic sexual orientation. Gender development might thus not always be typically female in CAIS suggesting a potential contribution of the sex chromosome genes as well. However, for the rest of this chapter when discussing the results of the different neuroimaging studies, we will refer to women with CAIS because they all identified themselves as women in these studies and expressed a very strong desire to be called women.

\subsection{The Sexual Differentiation of the Human Brain: Neuroimaging Studies in CAIS}

\subsubsection{Brain Function}

The introduction of neuroimaging techniques such as magnetic resonance imaging (MRI) has made it possible to study sex differences in brain structure and function in the general population but also in clinical populations. Functional MRI (fMRI) studies, which measure the activity of the brain while performing a task, have, for instance, shown that neural activity while viewing sexual images, emotional stimuli, or during the performance of spatial tasks such as a three-dimensional mental rotation task (MRT) differs between men and women (reviewed in Sacher et al. 2013). Furthermore, MRI studies of brain structure have shown sex differences in the volume of and structural connectivity between brain regions (Gong et al. 2011; Ruigrok et al. 2014). Women with CAIS provide a unique opportunity to study the 
origin of these sex differences and in particular to analyze the respective roles of sex chromosome genes versus androgens in the sexual differentiation of the human brain. At present, three independent groups (Hamann et al. 2014; van Hemmen et al. 2016, 2017b; Savic et al. 2017) have examined brain structure and function in CAIS using neuroimaging techniques. The fMRI study by Hamann et al. (2014) focused in particularly on brain responses to sexually arousing stimuli in light of the robust sex differences observed in this domain (e.g., Gizewski et al. 2009; Hamann et al. 2004). Men showed greater activation in the amygdala compared to control women and women with CAIS with the latter two groups not being any different. These results suggest that the male-typical activation most likely reflects androgen actions and thus no direct effects of genes of the Y chromosome. In addition, these data argue against an important role for brain aromatization in the masculinization of the brain as has been reported in some animal species (reviewed in Balthazart and Ball 2012) since women with CAIS have presumably higher brain estrogen levels derived from aromatization of testosterone but showed no signs of brain masculinization with regard to their responses to sexually arousing stimuli. However, all women with CAIS in this study (Hamann et al. 2014) identified themselves as women (gender identity and gender role) and were androphilic. They were also all raised as girls and received a female-typical socialization. Finally, it should be noted that group sizes were rather small ( $n=13$ /group) and there was no information available on whether the women with CAIS were gonadectomized and/or received any hormone replacement therapy (HRT) nor a confirmation of their diagnosis other than self-report.

As mentioned previously, men and women differ in cognitive abilities with the mental rotation task, a visuospatial task, often showing the greatest sex differences, with men generally outperforming women (Linn and Petersen 1985). Accordingly, fMRI studies have demonstrated sex differences in neural activation while performing this task, with generally higher levels of activation in parietal regions in men (Jordan et al. 2002; Weiss et al. 2003; Butler et al. 2006; Gizewski et al. 2006; Schöning et al. 2007; Hoppe et al. 2012). By contrast, several studies showed a greater activation in frontal and temporal brain regions in women (Thomsen et al. 2000; Jordan et al. 2002; Weiss et al. 2003; Seurinck et al. 2004; Kucian et al. 2005; Butler et al. 2006; Gizewski et al. 2006; Schöning et al. 2007; Hoppe et al. 2012). Based on these findings from both behavioral and neuroimaging studies, it has been proposed that men and women use different strategies for solving this task: women are thought to use a serial and analytical approach, whereas men are thought to rely on a more automatic "gestalt" strategy (Thomsen et al. 2000; Jordan et al. 2002; Butler et al. 2006). It has been hypothesized that these sex differences most likely reflect early androgen actions since it has been shown that women diagnosed with $\mathrm{CAH}$ outperformed their unaffected sisters on spatial tasks in childhood, adolescence, and adulthood (Puts et al. 2008; Berenbaum et al. 2012). In addition, men who have had low androgen levels throughout life due to idiopathic hypogonadotropic hypogonadism showed impaired spatial abilities compared with control men (Hier and Crowley 1982). Androgen replacement therapy in these men did not provide any consistent results (Hier and Crowley 1982; Zitzmann et al. 2001), which could also 
have been due to small sample sizes. The Wechsler Intelligence Scale for Adults (WAIS) and Wechsler Intelligence Scale for Children (WISC) have been used to study spatial abilities in women with CAIS. It was found that CAIS overall performed worse than control men and women (Imperato-McGinley et al. 1991; Masica et al. 1969). However, they were classified as being "feminine" based on their superior performance on verbal compared to spatial ability subtests. These results suggest that androgens and not sex chromosome genes play a predominant role in the masculinization of these behavioral and cognitive domains. To confirm this hypothesis, we compared brain activation during the performance of a 3D mental rotation task (MRT) in women with CAIS to control men and women (van Hemmen et al. 2016). We were able to recruit a total of 21 CAIS women, who were all gonadectomized and taking HRT (estrogens or combined estrogens/progestins) at the time of our study, and 30 control women and 30 control men. Groups were matched for age and educational level. The diagnosis of CAIS was based on both clinical characteristics and mutation analysis of the androgen receptor gene using genomic DNA. All participants received clear instructions for the MRT at the day of testing and performed a practice trial before the actual MRI session was started. The stimuli used were colored 3D objects (Shephard and Metzler 1971) with varying degrees of rotation ranging from $45^{\circ}$ to $315^{\circ}$. The stimuli were presented in an alternating block design with five rotation or control trials in each block. For the control trails, the participants just had to answer the question whether an arrow was pointing to the left or to the right. Response latency (reaction time) and accuracy were recorded. Significant differences were observed with control men responding faster than women with CAIS, but there were no group differences in accuracy scores. At the neural level, an overall similar activation pattern during mental rotation after subtraction of activation during the control condition was found: all groups showed bilateral activations in the parietal lobe, predominantly in inferior and superior regions, extending into the occipital lobe. Significant activations were also observed in frontal areas, to a large extent in the precentral and superior and middle frontal gyrus. The overall pattern observed is consistent with results from a meta-analysis on neuroimaging studies during mental rotation (Zachs 2008). Between group analyses using region of interest (ROIs) revealed sex differences with control men showing significantly more activation than control women in the left inferior parietal lobe and a trend for the right inferior lobe as well. Women with CAIS resembled control women in neural activation patterns and thus differed significantly from control men. We found no significant correlations between circulating hormone levels (testosterone, estradiol) and brain activation patterns. These results thus suggest that reported sex differences in brain functioning while performing a spatial ability task is not directly driven by genetic sex but might be attributable to gonadal hormone exposure, most likely androgens. The absence of male-typical results in CAIS further supports the notion that in humans, androgens, and not estrogens, are the masculinizing hormones. However, we cannot distinguish between organizational and activational effects of these androgens as the insensitivity to androgens is already present prenatally and remains continuous throughout life. Furthermore, women with CAIS have supposedly higher serum estrogen levels than men due to aromatization of testosterone when 
the gonads are still in situ (Hughes and Deeb 2006) and due to estrogen replacement therapy after gonadectomy. Thus the female-typical pattern in neural activation observed in CAIS can also be attributed to estradiol, which would be in line with studies that have proposed a role for estrogens in mental rotation-related neural activation and performance (e.g., Maki et al. 2002; Schöning et al. 2007), although it should be noted that others have not found these effects (e.g., Peters et al. 1995; Halari et al. 2005).

Finally, it cannot be ruled out that socialization has had an effect on brain activity as well. Exposure to typically masculine toys and activities is thought to have enhancing effects on performance on spatial tasks (e.g., Connor and Serbin 1977). Since recalled childhood toy and activity preferences were sex typical in our groups, i.e., there was a greater preference of masculine toys and activities in control men, and for feminine toys and activities in control women and women with CAIS. Gender stereotypes about male superiority on spatial tasks have also been proposed to affect the behavioral sex difference observed in the MRT (Hausmann et al. 2009). However, to minimize potential gender stereotype effects on the sex differences in neural activation, the participants were not informed about the sex difference in MRT performance before participation.

\subsubsection{Brain Structure}

Numerous neuroimaging studies have focused on macro- and mesoanatomical sex differences, such as in overall or regional gray (GM) and white matter (WM) volumes derived from structural MRI scans (for meta-analysis, see Ruigrok et al. 2014). Overall, it has been shown that men have larger bilateral GM volumes in limbic regions, including the amygdala, hippocampus, parahippocampal and cingulate gyrus, the temporal pole, precuneus, putamen, and cerebellum, whereas women have larger GM volumes in the bilateral thalamus and precuneus, right planum temporale/parietal operculum, insula, Heschl's and anterior cingulate gyrus, parts of the frontal cortex, and left parahippocampal gyrus and lateral occipital cortex. These sex differences are however not related to sex differences in total brain size (the male brain is on average $11 \%$ larger than the female brain). Evidence of early sex hormone effects on regional GM volumes seems to be rather inconsistent. In one study of boys (Lombardo et al. 2012), testosterone levels in amniotic fluid were associated with GM volume at age 8-11 in some, but not all brain regions showing sex differences. By contrast, no masculinizing effects of fetal testosterone on brain structure have been observed in girls diagnosed with $\mathrm{CAH}$, although a decrease in amygdala volume was observed in both boys and girls with $\mathrm{CAH}$ which is probably caused by their glucocorticoid deficiency (Merke et al. 2003). Some effects of circulating gonadal hormones on adult GM volumes have been reported (e.g., Lessov-Schlaggar et al. 2005; Witte et al. 2010; Lentini et al. 2012), but results varied among studies probably due to methodological differences.

In a recent study (Savic et al. 2017), cortical thickness and subcortical GM volumes were compared between a group of 16 women diagnosed with CAIS and 
control groups of men and women $(n=32 / \mathrm{sex})$. It was found that both women with CAIS and control women displayed thicker parietal and occipital cortices and a thinner left temporal cortex than control men. Interestingly, women with CAIS also displayed a "male" pattern, i.e., a significantly thinner cortex in the precentral gyrus and to some extent, in the postcentral gyrus compared to female control women, and thus similar to control men. Furthermore, caudate volumes were significantly smaller, i.e., "male-like," in women with CAIS compared to control women, but hippocampus volumes were female-like and thus significantly larger than in control men. Thus women with CAIS showed a mixed male and female pattern suggesting direct effects of sex chromosome genes in addition to sex hormone effects.

The MRI technique of diffusion tensor imaging (DTI), which measures the diffusion of water molecules, was recently developed to study sex differences in white matter microstructure. The most used quantitative measure that can be derived from DTI is fractional anisotropy (FA) (Pierpaoli and Basser 1996). The FA value provides information about the degree of diffusion anisotropy. A low FA value reflects isotropic diffusion, i.e., equal diffusion in all directions, as, for instance, in cerebrospinal fluid. A high degree of anisotropy is found in WM fiber bundles, in which water diffusion is restricted in the direction perpendicular to the axon. The majority of DTI studies have found higher FA values in major WM regions in men compared to women (e.g., Chou et al. 2011; Inano et al. 2011; Schoonheim et al. 2014; Takao et al. 2014). Lower FA values in WM tracts have been observed in women with Turner syndrome (Holzapfel et al. 2006) and men with Klinefelter syndrome (DeLisi et al. 2005), but these two DSDs are characterized by sex chromosome aneuploidies and subsequent sex hormone deficiencies, which makes it impossible to determine the relative contribution of sex chromosomes versus sex hormones in the sexual differentiation of WM characteristics. Therefore, to address this particular question, we acquired DTI scans of women with CAIS and compared them with groups of control men and women (van Hemmen et al. 2017b). The final sample consisted of 20 women with CAIS, 30 control men, and 30 control women.

Using analyses based on tract-based spatial statistics, widespread sex differences were observed in FA with control men showing higher FA values than control women in a single cluster covering a large part of the skeleton, including major WM tracts; subcortical regions, such as the bilateral thalamus and basal ganglia; and the brain stem. By contrast, control women did not show any regions with higher FA values than control men. Similar differences were found between control men and women with CAIS with control men having higher FA values in a large part of the skeleton, whereas the reverse contrast did not reveal any significant differences. Furthermore, no differences in FA values were observed between control women and women with CAIS. These findings thus suggest a more important role for sex hormones, most likely masculinizing androgen and/or feminizing estrogen effects, than for genetic effects related to sex chromosome genes in the sexual differentiation of WM microstructure.

A limitation of these studies (Hamann et al. 2014; van Hemmen et al. 2016, 2017b; Savic et al. 2017) conducted in women with CAIS that no inferences can 


\section{Findings in women with Complete Androgen Insensitivity Syndrome}

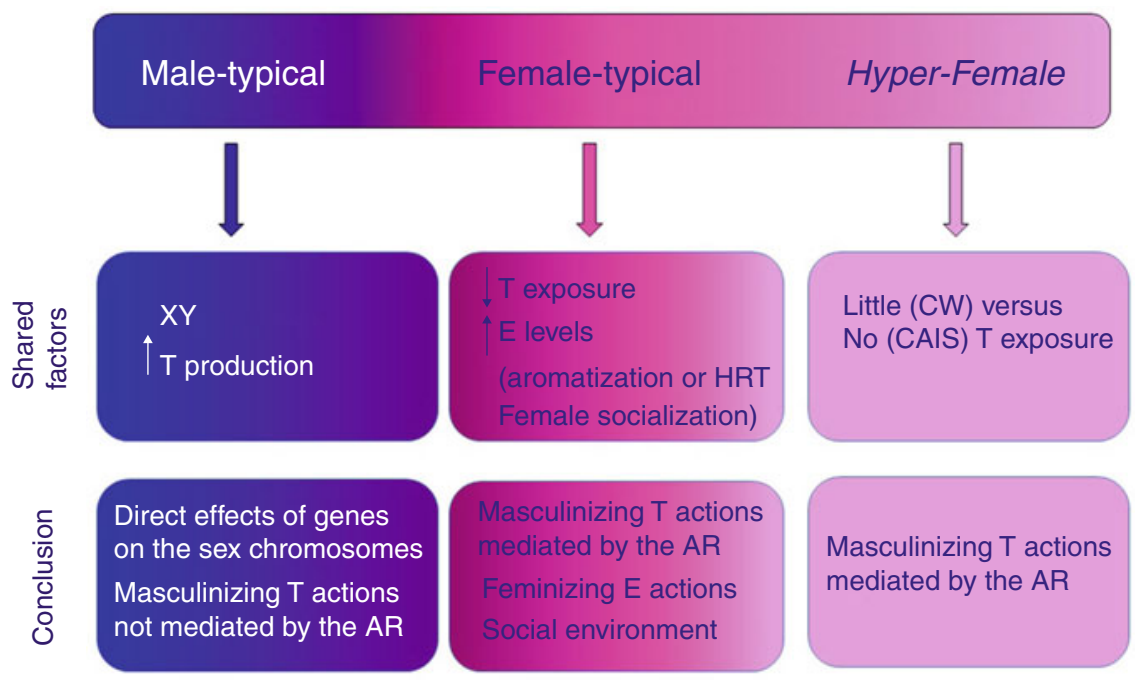

Fig. 1 Implications of male- and female-typical findings in women with CAIS. The upper boxes summarize the factors that women with CAIS share with the group of reference. In the lower boxes, the conclusions that can be drawn on these shared factors. $T$ testosterone, $A R$ androgen receptor, $E$ estrogen, $H R T$ hormone replacement therapy, $C W$ control women, $C A I S$ women with complete androgen insensitivity syndrome

be made about the exact timing of the proposed sex hormone effects. Since women with CAIS are insensitive to androgens throughout life, any finding obtained in adulthood can reflect organizational and/or activational sex hormone effects during the perinatal phase, adolescence, and/or adulthood. Longitudinal studies in women with CAIS, starting before adolescence, could provide important information regarding the timing of sex hormone effects on the sexual differentiation of the human brain.

To summarize, several sexually differentiated aspects of brain structure and function are female-typical in women with CAIS, although there is also evidence for male-typical neural characteristics. Female-typical findings in women with CAIS with respect to brain function were observed in the left inferior parietal lobe while performing a mental rotation task (van Hemmen et al. 2016) and in the amygdala when visualizing sexual images (Hamann et al. 2014). Regarding brain structure, a female-typical pattern was observed in regional GM volume of the hippocampus, as well as the parietal and occipital cortices (Savic et al. 2017), and in WM microstructure throughout extensive WM regions. By contrast, a maletypical caudate nucleus volume and pre- and postcentral gyrus cortex were observed in women with CAIS (Savic et al. 2017). These neuroimaging findings can be explained by several mechanisms (summarized in Fig. 1). Overall, neural development in the female direction in women with CAIS can be explained in three ways: (1) absence of masculinizing androgen effects following activation 
of the AR, (2) by feminizing estrogen effects derived from aromatization of androgens, and (3) by female-typical socialization. By contrast, male-typical neural and behavioral characteristics might be explained by (1) sex chromosome effects and (2) masculinizing androgen effects not mediated by the AR.

\subsubsection{Masculinizing Androgen Effects Mediated by the AR}

Nonfunctional ARs, caused by genetic mutations in the AR gene, result in a lack of effective androgen exposure. Even though the production of testosterone in women with CAIS is within or above the male range when their gonads are still in situ (Melo et al. 2003; Doehnert et al. 2015), these androgens have no direct effect on target tissues, because they cannot activate the AR. Consequently, if a sexually differentiated aspect of brain structure or function is female-typical in women with CAIS, this might reflect an important role for masculinizing androgen effects through AR activation in the sex-typical development of these structures and functions. These proposed androgen effects could be organizational, activational, or both. In addition, the role of the AR in the masculinization of the adolescent brain has been studied by looking specifically at a functional polymorphism of the AR gene: a low number of CAG repeats has been associated with stronger androgen signaling and vice versa (Hsiao et al. 1999; Irvine et al. 2000). It was found to modulate relative GM and WM volumes (Paus et al. 2010), cortical thickness development (Raznahan et al. 2010), and WM growth (Perrin et al. 2008). It should be noted that long CAG repeats of the AR have also been associated with male-tofemale transsexuality of which it has been hypothesized to reflect reduced androgen action during development (Hare et al. 2009).

Finally, since control women produce low amounts of androgens and have a functional AR, the level of androgen exposure differs between control women and women with CAIS. Therefore, in theory, the absence of any masculinizing androgen effects through the AR might result in "ultra-feminine" characteristics in women with CAIS (Fig. 1).

\subsubsection{Masculinizing Androgen Effects Not Mediated by the AR}

In general, it is difficult to determine whether potential androgen effects are the result of direct AR activation or indirect activation of the ER by androgen-derived estrogens upon aromatization, as is the predominant prenatal masculinizing pathway in rodent species (Bakker et al. 2006). It is, however, assumed that in humans masculinizing androgen effects are mediated by the AR and not the ER based on male-typical psychosexual development in men with aromatase deficiency or estrogen insensitivity due to a mutation in the estradiol receptor (Baum 2006), as well as on studies conducted in nonhuman primates (Wallen 2005). Previously reported predominant female-typical psychosexual characteristics in women with CAIS (Masica et al. 1971; Wisniewski et al. 2000; Hines et al. 2003; but see 
T'Sjoen et al. 2011; Brunner et al. 2016) also argue against a critical role for estrogens in brain masculinization in humans. Interestingly, it should be noted that there is some evidence for an activational role for estradiol on the brain in adult men. Indeed, a large clinical study (Finkelstein et al. 2013) showed that treatment with an aromatase inhibitor led to a significant decline in sexual desire in adult men.

\subsubsection{Feminizing Estrogen Effects}

Women with CAIS are thought to have higher estrogen levels than men because androgens produced by the gonads can be aromatized to estrogens and following gonadectomy, women with CAIS generally take estrogens from puberty onwards to induce puberty (in case of prepubertal gonadectomy) and to maintain their health. Therefore, female-typical neural characteristics might reflect feminizing effects of estrogens.

Recent studies in mice have shown that female-typical neural and behavioral characteristics develop under the influence of estradiol during a specific prepubertal period (Brock et al. 2010, 2011). These results thus challenged the classical view of a default organization of the female brain. To date, in humans, there is only evidence for a role of testosterone (and not estradiol) in the development of the human brain as mentioned above (e.g., Baum 2006). However, there is some indirect evidence that estradiol might play a role in the development of the female brain. Several studies (Downey et al. 1989; Rolstad et al. 2007; Shaeffer et al. 2008) have shown that TS women reported that aspects of heterosexual function (e.g., ever engaging in genital petting or sexual intercourse, ever having had a boyfriend) were significantly lower compared to control women. Furthermore, Ross et al. (1998) reported some beneficial effects of treatment with lose doses of estrogen at prepubertal ages on cognitive function. Twenty-four TS girls exhibited a significant improvement in their motor function and nonverbal processing speed after estradiol treatment, when compared to their TS peers who received a placebo treatment. Clearly more research is needed to determine whether estradiol feminizes the brain in humans.

\subsubsection{Socialization Effects}

A major challenge when studying potential biological factors underlying the sexual differentiation of the human brain and behavior is that from the moment someone is born, his/her social environment is gender-biased. Since women with CAIS are raised as girls, they share a female-typical socialization with control women. Thus, femaletypical findings in women with CAIS might reflect effects from the environment related to the gender of rearing. It has been thought that experience can alter the brain throughout life (e.g., Maguire et al. 2006), and gender-typical experiences might have an effect on sex differences found in brain structure and function. For example, exposure to male-typical toys and activities, such as playing action video games, might 
result in better performance on spatial tasks (Connor and Serbin 1977; Feng et al. 2007). However, there is also a very strong suggestion of early androgen effects in toy preferences: studies in girls with $\mathrm{CAH}$ have shown that they were more interested in playing with male-typical instead of female-typical toys (Hines et al. 2016).

\subsubsection{Sex Chromosome Effects}

The presence of some male-typical neural characteristics in women with CAIS might be explained by the fact that they have a Y chromosome. Although hormoneindependent effects of genes located on the sex chromosomes have long been overlooked as being relevant in brain sexual differentiation, recent animal studies have provided evidence for a role of sex chromosome genes in addition to sex hormone effects (e.g., Arnold and Chen 2009). Sexual differentiation as result of sex chromosome effects might reflect (1) direct effects of genes on the Y chromosome or (2) effects related to having one versus two X chromosomes. Studies in rodents have shown neural sex differences related to differences in Sry expression in the brain (Dewing et al. 2006). In individuals with two $X$ chromosomes, one of the two $X$ chromosomes is silenced to prevent higher expression of $\mathrm{X}$-linked genes in $\mathrm{XX}$ versus XY cells (Chang et al. 2006). This silencing is referred to as X-inactivation and serves as a mechanism to reduce sex differences. However, the gene responsible for X-inactivation, Xist, is only expressed in XX cells and has now been suggested as a potential sex-differentiating gene (Arnold 2017). Approximately 10-15\% of the X-linked genes escape X-inactivation (Carrel et al. 1999; Carrel and Willard 2005), of which some are located on the pseudoautosomal region (PAR), i.e., have Y-linked homologues, while others are outside the PAR (Disteche 2012). Higher expression of X-linked escapee genes located outside the PAR in XX versus XY cells may result in neural or behavioral sex differences. Furthermore, maternal versus paternal imprinting of the $\mathrm{X}$ chromosome might also influence sexual differentiation, as it might cause differences in expression of X-linked genes between men and women (Babak et al. 2015).

These proposed mechanisms of direct sex chromosome gene effects have not been adequately studied in humans yet, and even though animal studies have already provided some valuable information, many questions remain. A recent study using the FCG mouse model has shown that brain structure was related to sex hormone actions in 16, and sex hormone-independent effects in 11 brain regions (Corre et al. 2016) suggesting that the contribution of sex chromosome genes might still be underestimated (Arnold 2017). Human studies on cognitive abilities and brain structure and function in SCAs such as TS and KS have revealed a potential contribution of sex chromosome complement on, for example, verbal and spatial abilities and GM volume (reviewed in Printzlau et al. 2017), but these results remain difficult to interpret as they might also reflect sex hormone effects, since sex hormone levels are also affected in most SCAs. 


\section{Concluding Remarks}

Sex differences exist in many aspects of human behavior, cognition, and brain structure and function. It is of great importance to identify these factors causing sex differences, not only to increase our understanding of the development of the healthy brain but also to provide valuable information on the ontogeny of several neuropsychiatric disorders with an important sex difference in their prevalence. Neuroimaging studies in women with CAIS suggest that sex differences in the human brain results from a combination of sex hormone-, sex chromosome-, and socialization-related effects and that the relative contribution of each factor might vary throughout the brain. Nevertheless, androgens acting through the AR seem to play a major role in inducing male-typical neural and psychosexual characteristics in humans. By contrast, whether female-typical neural and psychosexual characteristics develop under the influence of estrogens remains to be elucidated.

\section{References}

Allen LS, Hines M, Shryne JE, Gorski RA (1989) Two sexually dimorphic cell groups in the human brain. J Neurosci 9:497-506

Arnold AP (2017) A general theory of sexual differentiation. J Neurosci Res 95:291-300

Arnold AP, Chen X (2009) What does the "four core genotypes" mouse model tell us about sex differences in the brain and other tissues? Front Neuroendocrinol 30:1-9

Arnold AP, Xu J, Grisham W, Chen X, Kim YH, Itoh Y (2004) Minireview: sex chromosomes and brain sexual differentiation. Endocrinology 145:1057-1062

Babak T, DeVeale B, Tsang EK, Zhou Y, Li X, Smith KS, Kukurba KR, Zhang R, Li JB, van der Kooy D, Montgomery SB, Fraser HB (2015) Genetic conflict reflected in tissue-specific maps of genomic imprinting in human and mouse. Nat Genet 47:544-549

Bakker J, Honda S, Harada N, Balthazart J (2002) The aromatase knockout mouse provides new evidence that estradiol is required during development for the expression of sociosexual behaviors in adulthood. J Neurosci 22:9104-9112

Bakker J, De Mees C, Douhard Q, Balthazart J, Gabant P, Szpirer J, Szpirer C (2006) Alphafetoprotein protects the developing female mouse brain from masculinization and defeminization by estrogens. Nat Neurosci 9:220-226

Balthazart J, Ball G (2012) Brain aromatase, estrogens, and behavior. Oxford University Press, Oxford

Bao A-M, Swaab DF (2011) Sexual differentiation of the human brain: relation to gender identity, sexual orientation and neuropsychiatric disorders. Front Neuroendocrinol 32:214-226

Baum MJ (1979) Differentiation of coital behavior in mammals: a comparative analysis. Neurosci Biobehav Rev 3:265-284

Baum MJ (2006) Mammalian animal models of psychosexual differentiation: when is translation to the human situation possible? Horm Behav 50:579-588

Berenbaum SA, Bryk KK, Nowak N, Quigley CA, Moffat S (2009) Fingers as a marker of prenatal androgen exposure. Endocrinology 150:5119-5124

Berenbaum SA, Bryk KLK, Beltz AM (2012) Early androgen effects on spatial and mechanical abilities: evidence from congenital adrenal hyperplasia. Behav Neurosci 126:86-96

Bertelloni S, Dati E, Baroncelli GI, Hiort O (2011) Hormonal management of complete androgen insensitivity syndrome from adolescence onward. Horm Res Paediatr 76:428-433 
Boehmer AL, Brüggenwirth H, van Assendelft C, Otten BJ, Verleun-Mooijman MC, Niermeijer MF, Brunner HG, Rouwé CW, Waelkens JJ, Oostdijk W, Kleijer WJ, van der Kwast TH, de Vroede MA, Drop SL (2001) Genotype versus phenotype in families with androgen insensitivity syndrome. J Clin Endocrinol Metab 86:4151-4160

Breedlove SM (2017) Prenatal influences on human sexual orientation: expectations versus data. Arch Sex Behav 46:1583-1592

Brock O, Douhard Q, Baum MJ, Bakker J (2010) Reduced prepubertal expression of progesterone receptor in the hypothalamus of female aromatase knockout mice. Endocrinology 151:1814-1821

Brock O, Baum MJ, Bakker J (2011) The development of female sexual behavior requires prepubertal estradiol. J Neurosci 31:5574-5578

Brunner F, Fliegner M, Krupp K, Rall K, Brucker S, Richter-Appelt H (2016) Gender role, gender identity and sexual orientation in CAIS ("XY-women") compared with subfertile and infertile 46,XX women. J Sex Res 53:109-124

Butler T, Imperato-McGinley J, Pan H, Voyer D, Cordero J, Zhu Y-S, Stern E, Silbersweig D (2006) Sex differences in mental rotation: top-down versus bottom-up processing. NeuroImage 32:445-456

Byne W, Tobet S, Mattiace LA, Lasco MS, Kemether E, Edgar MA, Morgello S, Buchsbaum MS, Jones LB (2001) The interstitial nuclei of the human anterior hypothalamus: an investigation of variation with sex, sexual orientation, and HIV status. Horm Behav 40:86-92

Carrel L, Willard HF (2005) X-inactivation profile reveals extensive variability in X-linked gene expression in females. Nature 434:400-404

Carrel L, Cottle AA, Goglin KC, Willard HF (1999) A first-generation X-inactivation profile of the human X chromosome. Proc Natl Acad Sci U S A 96:14440-14444

Chang SC, Tucker T, Thorogood NP, Brown CJ (2006) Mechanisms of X-chromosome inactivation. Front Biosci 11:852-866

Chou K-H, Cheng Y, Chen I-Y, Lin C-P, Chu W-C (2011) Sex-linked white matter microstructure of the social and analytic brain. NeuroImage 54:725-733

Collaer ML, Hines M (1995) Human behavioral sex differences: a role for gonadal hormones during early development? Psychol Bull 118:55-107

Connor JM, Serbin LA (1977) Behaviorally based masculine- and feminine-activity-preference scales for preschoolers: correlates with other classroom behaviors and cognitive tests. Child Dev 48:1411-1416

Cools M, Drop SLS, Wolffenbuttel KP, Oosterhuis JW, Looijenga LHJ (2006) Germ cell tumors in the intersex gonad: old paths, new directions, moving frontiers. Endocr Rev 27:468-484

Corre C, Friedel M, Vousden DA, Metcalf A, Spring S, Qiu LR, Lerc JP, Palmert MR (2016) Separate effects of sex hormones and sex chromosomes on brain structure and function revealed by high-resolution magnetic resonance imaging and spatial navigation of the Four Core Genotype mouse model. Brain Struct Funct 221:997-1016

Cosgrove KP, Mazure CM, Staley JK (2007) Evolving knowledge of sex differences in brain structure, function, and chemistry. Biol Psychiatry 62:847-855

Davis H (1983) An active process in cochlear mechanics. Hear Res 9:79-90

Davis SM, Rogol AD, Ross JL (2015) Testis development and fertility potential in boys with klinefelter syndrome. Endocrinol Metab Clin N Am 44:843-865

de Vries GJ, Rissman EF, Simerly EB, Yang LY, Scordalakes EM, Auger CJ, Swain A, LovellBadge R, Burgoyne PS, Arnold AP (2002) A model system for sex chromosome effects on sexually dimorphic neural and behavioral traits. J Neurosci 22:9005-9014

DeLisi LE, Maurizio AM, Svetina C, Ardekani B, Szulc K, Nierenberg J, Leonard J, Harvey PD (2005) Klinefelter's syndrome (XXY) as a genetic model for psychotic disorders. Am J Med Genet B Neuropsychiatr Genet 135B:15-23

Dewing P, Chiang CWK, Sinchak K, Sim H, Fernagut P-O, Kelly S, Chesselet M-F, Micevych PE, Albrecht KH, Harley VR, Vilain E (2006) Direct regulation of adult brain function by the male specific factor SRY. Curr Biol 16:415-420

Disteche CM (2012) Dosage compensation of the sex chromosomes. Annu Rev Genet 46:537-560 
Doehnert U, Bertelloni S, Werner R, Dati E, Hiort O (2015) Characteristic features of reproductive hormone profiles in late adolescent and adult females with complete androgen insensitivity syndrome. Sex Dev 9:69-74

Dörner G (1988) Neuroendocrine response to estrogen and brain differentiation in heterosexuals, homosexuals, and transsexuals. Arch Sex Behav 17:57-75

Downey J, Ehrhardt AA, Gruen R, Bell JJ, Morishima A (1989) Psychopathology and social functioning in women with Turner syndrome. J Nerv Ment Dis 177:191-201

Feder HH, Whalen RE (1964) Feminine behavior in neonatally castrated and estrogen-treated male rats. Science 147:306-307

Feng J, Spence I, Pratt J (2007) Playing an action video game reduces gender differences in spatial cognition. Psychol Sci 18:850-855

Finkelstein JS, Lee H, Burnett-Bowie SA, Pallais JC, Yu EW, Borges LF, Jones BF, Barry CV, Wulczyn KE, Thomas BJ, Leder BZ (2013) Gonadal steroids and body composition, strength, and sexual function in men. N Engl J Med 369:1011-1022

Garcia-Falgueras A, Swaab DF (2008) A sex difference in the hypothalamic uncinate nucleus: relationship to gender identity. Brain 131:3132-3146

Gizewski ER, Krause E, Wanke I, Forsting M, Senf W (2006) Gender-specific cerebral activation during cognitive tasks using functional MRI: comparison of women in mid-luteal phase and men. Neuroradiology 48:14-20

Gizewski ER, Krause E, Schlamann M, Happich F, Ladd ME, Forsting M, Senf W (2009) Specific cerebral activation due to visual erotic stimuli in male-to-female transsexuals compared with male and female controls: an fMRI study. J Sex Med 6:440-448

Gong G, He Y, Evans AC (2011) Brain connectivity: gender makes a difference. Neuroscientist 17:575-591

Grady KL, Phoenix CH, Young WC (1965) Role of the developing rat testis in differentiation of the neural tissues mediating mating behavior. J Comp Physiol Psychol 59:176-182

Halari R, Hines M, Kumari V, Mehrotra R, Wheeler M, Ng V, Sharma T (2005) Sex differences and individual differences in cognitive performance and their relationship to endogenous gonadal hormones and gonadotropins. Behav Neurosci 119:104-117

Hamann S, Herman RA, Nolan CL, Wallen K (2004) Men and women differ in amygdala response to visual sexual stimuli. Nat Neurosci 7:411-416

Hamann S, Stevens J, Vick JH, Bryk K, Quigley CA, Berenbaum SA, Wallen K (2014) Brain responses to sexual images in 46XY, women with complete androgen insensitivity syndrome are female-typical. Horm Behav 66:724-730

Hare L, Bernard P, Sanchez FJ, Baird PN, Vilain E, Kennedy T, Harley VR (2009) Androgen receptor repeat length polymorphism associated with male-to-female transsexualism. Biol Psychiatry 65:93-96

Hausmann M, Schoofs D, Rosenthal HES, Jordan K (2009) Interactive effects of sex hormones and gender stereotypes on cognitive sex differences - a psychobiosocial approach. Psychoneuroendocrinology 34:389-401

Hier DB, Crowley WF (1982) Spatial ability in androgen-deficient men. N Engl J Med 306:1202-1205

Hines M, Ahmed SF, Hughes IA (2003) Psychological outcomes and gender-related development in complete androgen insensitivity syndrome. Arch Sex Behav 32:93-101

Hines M, Pasterski V, Spencer D, Neufeld S, Patalay P, Hindmarsh PC, Hughes IA, Acerini CL (2016) Prenatal androgen exposure alters girls' responses to information regarding genderappropriate behaviour. Philos Trans R Soc B Biol Sci 371:20150125

Holzapfel M, Barnea-Goraly N, Eckert MA, Kesler SR, Reiss AL (2006) Selective alterations of white matter associated with visuospatial and sensorimotor dysfunction in Turner syndrome. J Neurosci 26:7007-7013

Hönekopp J, Watson S (2010) Meta-analysis of digit ratio 2D:4D shows greater sex difference in the right hand. Am J Hum Biol 22:619-630 
Hoppe C, Fliessbach K, Stausberg S, Stojanovic J, Trautner P, Elger CE, Weber B (2012) A key role for experimental task performance: effects of math talent, gender and performance on the neural correlates of mental rotation. Brain Cogn 78:14-27

Hsiao PW, Lin DL, Nakao R, Chang C (1999) The linkage of Kennedy's neuron disease to ARA24, the first identified androgen receptor polyglutamine region-associated coactivator. J Biol Chem 274:20229-20234

Hughes IA, Deeb A (2006) Androgen resistance. Best Pract Res Clin Endocrinol Metab 20:577-598

Hughes IA, Houk C, Ahmed SF, Lee PA (2006) Consensus statement on management of intersex disorders. J Pediatr Urol 2:148-162

Hughes IA, Davies JD, Bunch TI, Pasterski V, Mastroyannopoulou K, MacDougall J (2012) Androgen insensitivity syndrome. Lancet 380:1419-1428

Imperato-McGinley J, Pichardo M, Gautier T, Voyer D, Bryden MP (1991) Cognitive abilities in androgen-insensitive subjects: comparison with control males and females from the same kindred. Clin Endocrinol 34:341-347

Inano S, Takao H, Hayashi N, Abe O, Ohtomo K (2011) Effects of age and gender on white matter integrity. AJNR Am J Neuroradiol 32:2103-2109

Irvine RA, Ma H, Yu MC, Ross RK, Stallcup MR, Coetzee GA (2000) Inhibition of p160-mediated coactivation with increasing androgen receptor polyglutamine length. Hum Mol Genet 9:267-274

Jordan K, Wüstenberg T, Heinze HJ, Peters M, Jäncke L (2002) Women and men exhibit different cortical activation patterns during mental rotation tasks. Neuropsychologia 40:2397-2408

Kemp DT (1978) Stimulated acoustic emissions from within the human auditory system. J Acoust Soc Am 64:1386-1391

Kemp DT (2008) Otoacoustic emissions: concepts and origins. In: Manley GA, Fay RR, Popper AN (eds) Active processes and otoacoustic emissions in hearing. Springer handbook of auditory research. Springer, New York, pp 1-38

Koopman P, Munsterberg A, Capel B, Vivian N, Lovell-Badge R (1990) Expression of a candidate sex-determining gene during mouse testis differentiation. Nature 348:450-452

Kruijver FP, Zhou JN, Pool CW, Hofman MA, Gooren LJ, Swaab DF (2000) Male-to-female transsexuals have female neuron numbers in a limbic nucleus. J Clin Endocrinol Metab 85:2034-2041

Kucian K, Loenneker T, Dietrich T, Martin E, von Aster M (2005) Gender differences in brain activation patterns during mental rotation and number related cognitive tasks. Psychol Sci 47:112-131

Kuiri-Hänninen T, Sankilampi U, Dunkel L (2014) Activation of the hypothalamic-pituitarygonadal axis in infancy: minipuberty. Horm Res Paediatr 82:73-80

Lamprecht SA, Kohen F, Ausher J, Zor U, Lindner HR (1976) Hormonal stimulation of oestradiol17 beta release from the rat ovary during early postnatal development. J Endocrinol 68:343-344

Lee PA, Nordenström A, Houk CP, Ahmed SF, Auchus R, Baratz A, Baratz Dalke K, Liao L-M, Lin-Su K, Looijenga LHJ, Mazur T, Meyer-Bahlburg HFL, Mouriquand P, Quigley CA, Sandberg DE, Vilain E, Witchel S (2016) Global disorders of sex development update since 2006: perceptions, approach and care. Horm Res Paediatr 85:158-180

Lentini E, Kasahara M, Arver S, Savic I (2012) Sex differences in the human brain and the impact of sex chromosomes and sex hormones. Cereb Cortex 23:2322-2336

Lessov-Schlaggar CN, Reed T, Swan GE, Krasnow RE, DeCarli C, Marcus R, Holloway L, Wolf PA, Carmelli D (2005) Association of sex steroid hormones with brain morphology and cognition in healthy elderly men. Neurology 65:1591-1596

LeVay S (1991) A difference in hypothalamic structure between heterosexual and homosexual men. Science 253:1034-1037

Linn MC, Petersen AC (1985) Emergence and characterization of sex differences in spatial ability: a meta-analysis. Child Dev 56:1479-1498 
The Sexual Differentiation of the Human Brain: Role of Sex Hormones...

Lombardo MV, Ashwin E, Auyeung B, Chakrabarti B, Taylor K, Hackett G, Bullmore ET, BaronCohen S (2012) Fetal testosterone influences sexually dimorphic gray matter in the human brain. J Neurosci 32:674-680

Lutchmaya S, Baron-Cohen S, Raggatt P, Knickmeyer R, Manning JT (2004) 2nd to 4th digit ratios, fetal testosterone and estradiol. Early Hum Dev 77:23-28

Maccoby EE, Jacklin CN (1974) The psychology of sex differences. Stanford University Press, Palo Alto

Maguire EA, Woollett K, Spiers HJ (2006) London taxi drivers and bus drivers: a structural MRI and neuropsychological analysis. Hippocampus 16:1091-1101

Maki PM, Rich JB, Shayna Rosenbaum R (2002) Implicit memory varies across the menstrual cycle: estrogen effects in young women. Neuropsychologia 40:518-529

Masica DN, Money J, Ehrhardt AA, Lewis VG (1969) IQ, fetal sex hormones and cognitive patterns: studies in the testicular feminizing syndrome of androgen insensitivity. Johns Hopkins Med J 124:34-43

Masica DN, Money J, Ehrhardt AA (1971) Fetal feminization and female gender identity in the testicular feminizing syndrome of androgen insensitivity. Arch Sex Behav 1:131-142

McFadden D, Pasanen EG (1998) Comparison of the auditory systems of heterosexuals and homosexuals: click-evoked otoacoustic emissions. Proc Natl Acad Sci U S A 95:2709-2713

Melo KFS, Mendonca BB, Billerbeck AEC, Costa EMF, Inacio M, Sliva FAQ, Leal AMO, Latronico AC, Arnhold IJP (2003) Clinical, hormonal, behavioral, and genetic characteristics of androgen insensitivity syndrome in a Brazilian cohort: five novel mutations in the androgen receptor gene. J Clin Endocrinol Metab 88:3241-3250

Merke DP, Fields JD, Keil MF, Vaituzis AC, Chrousos GP, Giedd JN (2003) Children with classic congenital adrenal hyperplasia have decreased amygdala volume: potential prenatal and postnatal hormonal effects. J Clin Endocrinol Metab 88:1760-1765

Meyer-Bahlburg HFL, Dolezal C, Baker SW, New MI (2008) Sexual orientation in women with classical or non-classical congenital adrenal hyperplasia as a function of degree of prenatal androgen excess. Arch Sex Behav 37:85-99

Modi DN, Sane S, Bhartiya D (2003) Accelerated germ cell apoptosis in sex chromosome aneuploid fetal human gonads. Mol Hum Reprod 9:219-225

Morris JA, Jordan CL, Breedlove SM (2004) Sexual differentiation of the vertebrate nervous system. Nat Neurosci 7:1034-1039

Nagamani M, McDonough PG, Ellegood JO, Mahesh VB (1979) Maternal and amniotic fluid steroids throughout human pregnancy. Am J Obstet Gynecol 134:674-680

Pasterski VL, Geffner ME, Brain C, Hindmarsh P, Brook C, Hines M (2005) Prenatal hormones and postnatal socialization by parents as determinants of male-typical toy play in girls with congenital adrenal hyperplasia. Child Dev 76:264-278

Paus T, Nawaz-Khan I, Leonard G, Perron M, Pike GB, Pitiot A, Richer L, Susman E, Weillette S, Pausova Z (2010) Sexual dimorphism in the adolescent brain: role of testosterone and androgen receptor in global and local volumes of grey and white matter. Horm Behav 57:63-75

Perrin JS, Hervé P-Y, Leonard G, Perron M, Pike GB, Pitiot A, Richer L, Veillette S, Pausova Z, Paus T (2008) Growth of white matter in the adolescent brain: role of testosterone and androgen receptor. J Neuro-Oncol 28:9519-9524

Peters M, Laeng B, Latham K, Jackson M, Zaiyouna R, Richardson C (1995) A redrawn Vandenberg and Kuse mental rotation test: different versions and factors that affect performance. Brain Cogn 28:39-58

Pierpaoli C, Basser PJ (1996) Toward a quantitative assessment of diffusion anisotropy. Magn Reson Med 36:893-906

Printzlau F, Wolstencroft J, Skuse DH (2017) Cognitive, behavioral and neural consequences of sex chromosome aneuploidy. J Neurosci Res 95:311-319

Puts DA, McDaniel MA, Jordan CL, Breedlove SM (2008) Spatial ability and prenatal androgens: meta-analyses of congenital adrenal hyperplasia and digit ratio (2D:4D) studies. Arch Sex Behav 37:100-111 
Raznahan A, Lee Y, Stidd R, Long R, Greenstein D, Clasen L, Addington A, Gogtay N, Rapoport JL, Giedd JN (2010) Longitudinally mapping the influence of sex and androgen signaling on the dynamics of human cortical maturation in adolescence. Proc Natl Acad Sci U S A 107:16988-16993

Reyes FI, Boroditsky RS, Winter JS, Faiman C (1974) Studies on human sexual development. II. Fetal and maternal serum gonadotropin and sex steroid concentrations. J Clin Endocrinol Metab 38:612-617

Rolstad SG, Moller A, Bryman I, Boman UW (2007) Sexual functioning and partner relationships in women with Turner syndrome: some empirical data and theoretical considerations regarding sexual desire. J Sex Marital Ther 33:231-247

Ross JL, Roeltgen D, Feuillan P, Kushner H, Cutler GB (1998) Effects of estrogen on nonverbal processing speed and motor function in girls with Turner's Syndrome. J Clin Endocrinol Metab 83:3198-3204

Ruigrok ANV, Salimi-Khorshidi G, Lai M-C, Baron-Cohen S, Lombardo MV, Tait RJ, Suckling J (2014) A meta-analysis of sex differences in human brain structure. Neurosci Biobehav Rev 39:34-50

Sacher J, Neumann J, Okon-Singer H, Gotowiec S, Villringer A (2013) Sexual dimorphism in the human brain: evidence from neuroimaging. Magn Reson Imaging 31:366-375

Savic I, Frisen L, Manzouri A, Nordenstrom A, Lindén Hirschberg A (2017) Role of testosterone and $\mathrm{Y}$ chromosome genes for the masculinization of the human brain. Hum Brain Mapp 38:1801-1814

Schirmer A, Zysset S, Kotz SA, Yves von Cramon D (2004) Gender differences in the activation of inferior frontal cortex during emotional speech perception. NeuroImage 21:1114-1123

Schöning S, Engelien A, Kugel H, Schäfer S, Schiffbauer H, Zwitserlood P, Pletziger E, Beizai P, Kersting A, Ohrann P (2007) Functional anatomy of visuo-spatial working memory during mental rotation is influenced by sex, menstrual cycle, and sex steroid hormones. Neuropsychologia 45:3203-3214

Schoonheim MM, Rueda Lopes FC, Pouwels PJW, Polman CH, Barkhof F, Geurts JJG (2014) Sex-specific extent and severity of white matter damage in multiple sclerosis: implications for cognitive decline. Hum Brain Mapp 35:2348-2358

Seurinck R, Vingerhoets G, de Lange FP, Achten E (2004) Does egocentric mental rotation elicit sex differences? NeuroImage 23:1440-1449

Shaeffer AT, Lange E, Bondy CA (2008) Sexual function in women with Turner syndrome. J Womens Health 17:27-33

Shephard RN, Metzler J (1971) Mental rotation of three-dimensional objects. Science 171:701-703

Shinur AWK, Hampson E (2011) Sex and ear differences in spontaneous and click-evoked otoacoustic emissions in young adults. Brain Cogn 77:40-47

Swaab DF (2007) Sexual differentiation of the brain and behavior. Best Pract Res Clin Endocrinol Metab 21:431-444

Swaab DF, Hofman MA (1990) An enlarged suprachiasmatic nucleus in homosexual men. Brain Res 537:141-148

T'Sjoen G, de Cuypere G, Monstrey S, Hoebeke P, Freedman FK, Appari M, Holterhus P-M, van Borsel J, Cools M (2011) Male gender identity in complete androgen insensitivity syndrome. Arch Sex Behav 40:635-638

Tadokoro-Cuccaro R, Hughes IA (2014) Androgen insensitivity syndrome. Curr Opin Endocrinol Diabetes Obes 21:499-503

Takao H, Hayashi N, Ohtomo K (2014) Sex dimorphism in the white matter: fractional anisotropy and brain size. J Magn Reson Imaging 39:917-923

Taziaux M, Swaab DF, Bakker J (2012) Sex differences in the neurokinin B system in the human infundibular nucleus. J Clin Endocrinol Metab 97:E2210-E2220

Taziaux M, Staphorsius AS, Ghatei MA, Bloom SR, Swaab DF, Bakker J (2016) Kisspeptin expression in the human infundibular nucleus in relation to sex, gender identity, and sexual orientation. J Clin Endocrinol Metab 101:2380-2389 
Thomsen T, Hugdahl K, Ersland L, Barndon R, Lundervold A, Smievoll AI, Roscher BE, Sundberg H (2000) Functional magnetic resonance imaging (fMRI) study of sex differences in a mental rotation task. Med Sci Monit 6:1186-1196

van Hemmen J, Veltman DJ, Hoekzema E, Cohen-Kettenis PT, Dessens AB (2016) Neural activation during mental rotation in complete androgen insensitivity syndrome: the influence of sex hormones and sex chromosomes. Cereb Cortex 26:1036-1045

van Hemmen J, Cohen-Kettenis PT, Steensma TD, Veltman DJ, Bakker J (2017a) Do sex differences in CEOAEs and 2D:4D ratios reflect androgen exposure? A study in women with complete androgen insensitivity syndrome. Biol Sex Differ 8:11

van Hemmen J, Saris IMJ, Cohen-Kettenis PT, Veltman DJ, Pouwels PJW, Bakker J (2017b) Sex differences in white matter microstructure in the human brain predominantly reflect differences in sex hormone exposure. Cereb Cortex 27:2994-3001

Ventura T, Gomes MC, Pita A, Neto MT, Taylor A (2013) Digit ratio (2D,4D) in newborns: influences of prenatal testosterone and maternal environment. Early Hum Dev 89:107-112

Wallen K (2005) Hormonal influences on sexually differentiated behavior in nonhuman primates. Front Neuroendocrinol 26:7-26

Weiss E, Siedentopf CM, Hofer A, Deisenhammer EA, Hoptman MJ, Kremser C, Golaszewski S, Felber S, Fleischhacker WW, Delazer M (2003) Sex differences in brain activation pattern during a visuospatial cognitive task: a functional magnetic resonance imaging study in healthy volunteers. Neurosci Lett 344:169-172

Winter JS, Hughes IA, Reyes FI, Faiman C (1976) Pituitary-gonadal relations in infancy: 2. Patterns of serum gonadal steroid concentrations in man from birth to two years of age. J Clin Endocrinol Metab 42:679-686

Wisniewski AB, Migeon CJ, Meyer-Bahlburg HF, Gearhart JP, Berkovitz GD, Brown TR, Money J (2000) Complete androgen insensitivity syndrome: long-term medical, surgical, and psychosexual outcome. J Clin Endocrinol Metab 85:2664-2669

Witte AV, Savli M, Holik A, Kasper S, Lanzenberger R (2010) Regional sex differences in grey matter volume are associated with sex hormones in the young adult human brain. NeuroImage 49:1205-1212

Zachmann M, Prader A, Sobel EH, Crigler JF Jr, Ritzen EM, Atares M, Ferrandez A (1986) Pubertal growth in patients with androgen insensitivity: indirect evidence for the importance of estrogens in pubertal growth of girls. J Pediatr 108:694-697

Zachs JM (2008) Neuroimaging studies of mental rotation: a meta-analysis and review. J Cogn Neurosci 20:1-19

Zhou JN, Hofman MA, Gooren LJ, Swaab DF (1995) A sex difference in the human brain and its relation to transsexuality. Nature 378:68-70

Zitzmann M, Weckesser M, Schober O, Nieschlag E (2001) Changes in cerebral glucose metabolism and visuospatial capability in hypogonadal males under testosterone substitution. Exp Clin Endocrinol Diabetes 109:302-304 